\title{
Failure to find statistical significance in left-handedness and pathology studies: A forgotten consideration
}

\author{
STANLEY COREN \\ University of British Columbia, Vancouver, British Columbia, Canada
}

\begin{abstract}
In the current controversy over left-handedness as a marker for various pathological conditions, a number of published studies have failed to replicate associations between handedness and various risk factors reported by other investigators. This paper demonstrates that many of these studies have simply lacked the statistical power to do so. As demonstrated here, the problem usually consists of inadequate sample sizes for the conditions. For example, given a sample of 1,000 subjects and a true rate of pathology of $10 \%$ in right-handers, even if left-handers have a 50\% higher risk (true rate of pathology, 15\%) the statistical power is only .3. This means that this difference would not reach statistical significance at $p<.05$ in $70 \%$ of the studies with a sample of this size! A figure allowing estimation of statistical power under typical conditions associated with handedness research is provided.
\end{abstract}

There is an ongoing controversy about the significance of left-handedness as a marker for various physical and psychological risks. Recent considerations of this issue usually begin with the now often replicated finding that there is a diminishing percentage of left-handers in older age groups (e.g., Coren \& Porac, 1979; Ellis, Ellis, \& Marshall, 1988; Fleminger, Dalton \& Standage, 1977; Gilbert \& Wysocki, 1992; Lansky, Feinstein, \& Peterson, 1988; Porac \& Coren, 1981; Porac, Coren, \& Duncan, 1980; Smart, Jeffrey, \& Richards, 1980). To explain this age trend, some researchers have suggested the elimination hypothesis, which maintains that left-handers are disappearing from the population because of a higher risk of early death (e.g., Coren, 1992; Coren \& Halpern, 1991). Evidence supporting this conclusion comes from archival studies of the life span of baseball and cricket players (Aggleton, Kentridge, \& Neave, in press; Halpern \& Coren, 1988) and examinations of randomly selected death records (Halpern \& Coren, 1991). Both types of study confirm that the mean age of death of left-handers is lower than that of right-handers.

Those favoring the elimination hypothesis have argued that this reduced life span in left-handers is due to a number of risk factors. There is evidence that left-handedness is often associated with prenatal and perinatal stressors (e.g., low birth weight, prolonged labor, birth-related anoxias, $\mathrm{Rh}$ incompatibilities, and older age of the mother; see Bakan, 1990; Coren, 1990; Coren \& Porac, 1980;

\footnotetext{
This work was supported in part by grants from the Medical Research Council of Canada and the Natural Sciences and Engineering Research Council of Canada. Address for reprints and correspondence: S. Coren, University of British Columbia, Department of Psychology, 2136 West Mall, Vancouver, BC, Canada V6T 1 Z4.
}

Searleman, Porac, \& Coren, 1989). It is argued that lefthandedness is a marker for neural pathology that has resulted from such stressors (Coren, 1992; Coren \& Searleman, 1990) and that it may signal the existence of additional pathology in other physiological systems. This corollary pathology, in turn, may result in greater mortality risk. Consistent with this line of argument are reports that left-handedness is associated with increased allergies, higher risk of immune disorders (Chengappa et al., 1992; Coren \& Halpern, 1991; Geschwind \& Galaburda, 1987; Habib, Touze, \& Galaburda, 1990; Searleman \& Fugagli, 1987), and a variety of other physical problems (see Coren, 1992, for a review).

Another set of data supporting the elimination hypothesis is the observation that left-handers are more likely to suffer from accidents causing physical damage (Coren, 1989; Daniel, Yeo, \& Gangestad, 1992; Graham, Glenn, Dick, Allen, \& Pasley, 1992). Most important in this regard is the fact that sinistrals are more likely to die of accidental injury (Aggleton et al., in press; Halpern \& Coren, 1991).

There has been no universal replication of any of these findings, however. Thus we find that in some reports, an increased association of left-handedness with birth stress (e.g., Schwartz, 1990), allergies and immune disorders (e.g., Betancur, Velez, Cabanieu, LeMoal, \& Neveu, 1990; Berge \& Segalowitz, 1992; Chavance, 1990), rate of death (Kuhlemeir, 1991), or accidents (Peters \& Perry, 1991), for example, has not been replicated. The absence of statistical significance from such studies has been treated by some authors as hard evidence that the elimination hypothesis is wrong. Unfortunately, this conclusion is unwarranted, because of considerations of statistical power that are especially important given the nature of handedness data. 
Consider the sample sizes involved in these studies that I have selected as being typical of reports of nonsignificance. For Schwartz (1990), most comparisons are based on around 200 cases; for Betancur et al. (1990), 464 cases; for Berge and Segalowitz (1992), 287 cases; for Chavance et al. (1990), most comparisons involve around 380 cases; for Kuhlemeir (1991), the conclusions are based on 366 deaths; and for Peters and Perry (1991), 1,021 cases. By the standards of most psychology experiments, these appear to be large sample sizes, but when one is testing hypotheses associated with handedness, such sample sizes are really quite small and the statistical power is quite low.

Let us see why this is the case. Suppose that we begin with a random sample of 1,000 subjects. The usual base rates will be around $10 \%$ left-handed, so we actually end up with around 900 right-handers and only 100 lefthanders. Suppose that the base rate of the pathology that we are looking at is $10 \%$. This value is typical of many pathological rates in the full population (e.g., people with allergies, people injured in accidents, migraine headache sufferers, etc.), but it is actually too high for some of the more interesting conditions (e.g., asthma, diabetes, myasthenia gravis, etc.). This would give us (under the null hypothesis of no difference) 90 right-handed and 10 lefthanded individuals suffering from the pathology. Looking at these small final samples for cases with pathology, one can begin to anticipate that there may be statistical problems, especially given the fact that we will be using frequency analyses (e.g., chi-squares) that are more insensitive than tests based on continuous interval measures.

To continue with our example, suppose that the true rate of pathology is really very different for the two samples. Assume that, on the average, the probability that left-handers will manifest the pathology is $50 \%$ higher. This means that, on the average, we will be looking at pathology percentages of $10 \%$ for right-handers versus $15 \%$ for left-handers. For the sample size of 1,000 that we began with, even this massive difference is still not statistically significant for a test of difference between independent proportions producing only a $z=1.55$.

To assist in assessing the statistical power of various samples in typical handedness research, I have prepared Figure 1, using the procedures provided by Bornstein and Cohen (1990). This figure allows one to estimate the statistical power for various sample sizes under the assumptions that the actual rate of left-handedness in the general population is about $10 \%$ and the rate of pathology in the

\section{POWER ANALYSIS}

Rate of Left-handedness is 10 Percent

Right-hander Baseline is 10 Percent

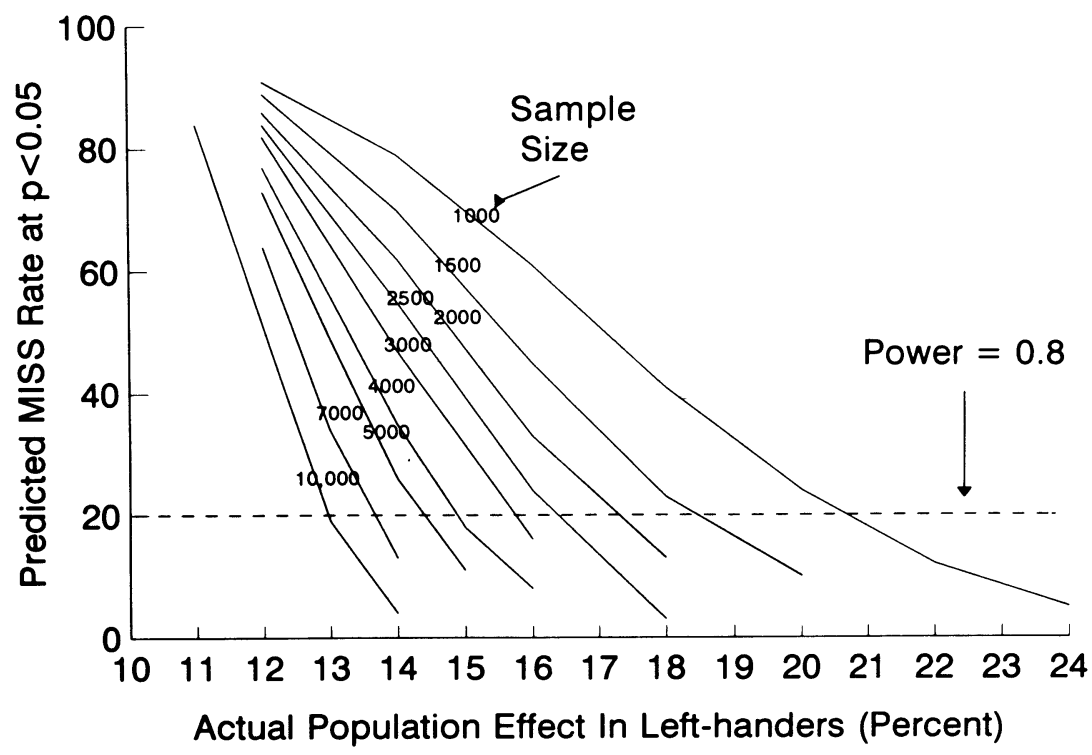

Figure 1. This set of curves can be used to compute statistical power in a typical handedness study, as follows: With the rate of pathology at $10 \%$ for right-handers, find the true rate of pathology in left-handers on the abscissa, then erect a vertical line. At the point of intersection between the vertical and the sample size, draw a horizontal line. The intersection of the horizontal with the ordinate indicates the expected experimental miss rate ( $p$ not less than $\mathbf{. 0 5}$ ). To find the optimal sample size for any given effect size, note the point of intersection between the true rate of pathology in left-handers and the .8 power line. 
right-handed population is about $10 \%$, which are reasonable starting estimates for many studies of pathology and handedness. Statistical power is defined in terms of the proportion of times that random samples would achieve statistical significance if the actual population effect among left-handers was that indicated on the abscissa. Power is actually one minus the proportion of expected misses, where a miss is defined as a sample in which the significance of the differences between the groups does not reach $p<.05$ despite a true difference in population proportions. One accepted value for adequate power in a study is .8 , which is equivalent to missing a true difference only $20 \%$ of the time.

To use the figure, let us return to our example, where we have a sample size of 1,000 and the true population rate for pathology in right-handers is $10 \%$ pathology and in left-handers $15 \%$. One need only erect a vertical line from the population value on the abscissa (15\%) and note the point of intersection with the sample size line $(1,000)$. A horizontal from this point to the ordinate shows that the expected miss rate for statistical significance with $p<$ .05 is $70 \%$, meaning that the statistical power is only .3 . In other words, with a true population rate where lefthanders are $50 \%$ more likely to be pathological, sample differences will be statistically significant only 3 times out of 10 with a sample size of 1,000 ! For a statistical power of .8 with this sample size, left-handers would have to show $21 \%$ pathology-that is, a $110 \%$ increase over the right-hander base rate (as shown by the point where the dotted line representing a power of .8 intersects the 1,000 sample size line, from which one drops a vertical to the abscissa). Alternatively, one can read from the figure that the sample size needed for this magnitude of difference to achieve a power of .8 is 5,000 .

A quick reconsideration of the sample sizes of the studies that have shown nonsignificant relationships between handedness and various conditions shows that the average sample has been under 500 . One might ask, then, whether it is any wonder that these studies have reported nonsignificance. At a sample size of 500 , even if lefthanders were twice as likely as right-handers to show pathology (i.e., a true population percentage of $20 \%$ ), the difference would still miss significance $53 \%$ of the time (power is .47).

Assertions of the null hypothesis are always fraught with problems, as any basic statistical textbook will say. Assertions of the null hypothesis under the conditions associated with a typical handedness and pathology experiment are even more problematic, as I have shown here. Obviously, studies that have found statistical significance with smaller samples (around 1,000 subjects or less) must have been dealing with massive differences in the relative risk of right- versus left-handers. For this reason, reports that find no statistical difference should not be used to offset the significant findings, unless they can demonstrate sufficient statistical power to provide a credible test.

Perhaps, at the very least, experimental reports asserting the null hypothesis in handedness studies ought to give us the power estimates for their study and conditions. In this way, readers could at least assess the sensitivity of the experimental design. Obviously, if a study has a sample size that will miss a true significant difference between groups when one group has a $50 \%$ higher risk, and if the study will do this $70 \%$ of the time, it does not seem sensible to publish a report of such nonsignificant findings as a contribution to the literature. Yet, in many studies dealing with handedness as a marker for pathological conditions, this is exactly what is currently being done in many journals.

\section{REFERENCES}

Aggleton, J. P., Kentridge, R. W., \& Neave, N. J. (in press). Evidence for longevity differences between left- and right-handed men: An archival study of cricketers. Journal of Epidemiology \& Community Health.

BAKAN, P. (1990). Nonright-handedness and the continuum of reproductive casualty. In S. Coren (Ed.), Left-handedness: Behavioral implications and anomalies (Advances in Psychology, No. 67, pp. 33-74). Amsterdam: North-Holland.

Berge, B., \& Segalowitz, S. (1992). The power of the GeschwindBehan hypothesis? Journal of Clinical \& Experimental Neuropsychology, 14, 117-118.

Betancur, C., Velez, A., Cabanieu, G., LeMoal, M., \& Neveu, P. J. (1990). Association between left-handedness and allergy: A reappraisal. Neuropsychologia, 28, 223-227.

BORENSTEIN, M., \& COHEN, J. (1990). Statistical power analysis. Hillsdale, NJ: Erlbaum.

Chavance, M., Dellatolas, G., Bousser, M. G., Amor, B., Gradel, B., Kahan, A., Kahn, M. F., LeFloch, J. P., \& TCHOBRoutsKY, G. (1990). Handedness, immune disorder and information bias. Neuropsychologia, 28, 429-441.

Chengappa, K. N. R., Ganguli, R., Yang, Z. W., Schurin, G., Cochran, J., BraR, J. S., \& RABIN, R. (1992). Non-right-sidedness: An association with lower IL-2 production. Life Sciences, 51, 1843-1849.

COREN, S. (1989). Left-handedness and accident-related injury risk. American Journal of Public Health, 79, 1040-1041.

CoREN, S. (1990). Relative risk of left-handedness in offspring as a function of maternal age at parturition. New England Journal of Medicine, 322, 1673.

COREN, S. (1992). The left-hander syndrome: The causes and consequences of left-handedness. New York: Free Press.

Coren, S., \& HalPern, D. F. (1991). Left-handedness: A marker for decreased survival fitness. Psychological Bulletin, 109, 90-106.

Coren, S. , \& Porac, C. (1979). Normative data on hand position during writing. Cortex, 15, 679-682.

Coren, S., \& Porac, C. (1980). Birth factors and laterality: Effects of birth order, parental age, and birth stress on four indices of lateral preference. Behavior Genetics, 10, 123-138.

Coren, S., \& Searleman, A. (1990). Birth stress and left-handedness: The rare trait marker model. In S. Coren (Ed.), Left-handedness: Behavioral implications and anomalies (Advances in Psychology, No. 67, pp. 3-32). Amsterdam: North-Holland.

Daniel, W. F., Yeo, R. A., \& Gangestad, S. W. (1992). Left-handers suffer more head injuries than do right-handers. Journal of Clinical \& Experimental Neuropsychology, 14, 77.

Ellis, S. J., Ellis, P. J., \& Marshall, E. (1988). Hand preference in a normal population. Cortex, 24, 157-163.

Fleminger, J. J., Dalton, R., \& Standage, K. F. (1977). Age as a factor in the handedness of adults. Neuropsychologia, 15, 471-473.

Geschwind, N., \& Galaburda, A. M. (1987). Cerebral lateralization: Biological mechanisms, associations, and pathology. Cambridge, MA: MIT Press.

GILBERT, N. N., \& WYSOCKI, C. J. (1992). Hand preference and age in the United States. Neuropsychologia, 30, 601-608. 
Graham, C. J., Glenn, R., Dick, R., Allen, B., \& Pasley, J. (1992). Left-handedness as a risk factor for accidental trauma. American Journal of Diseases of Children, 146, 465-466.

Habib, M., Touze, F., \& GalabURDA, A. M. (1990). Intrauterine factors in sinistrality: A review. In S. Coren (Ed.), Left-handedness: Behavioral implications and anomalies (Advances in Psychology, No. 67, pp. 99-130). Amsterdam: North-Holland.

HALPERN, D. F., \& COREN, S. (1988). Do right-handers live longer? Nature, 333, 213.

HalPeRn, D. F., \& CoRen, S. (1991). Hand preference and life span. New England Journal of Medicine, 324, 998.

Kuhlemeir, K. V. (1991). Longevity and left-handedness. American Journal of Public Health, 81, 513-514.

Lansky, L. M., Feinstein, H., \& Peterson, J. (1988). Demography of handedness in two samples of randomly selected adults $(N=2,083)$. Neuropsychologia, 26, 465-477.

Peters, M., \& Perry, R. (1991). No link between left-handedness and maternal age and no elevated accident rate in left-handers. Neuropsychologia, 29, 1257-1259.
Porac, C., \& CoREN, S. (1981). Lateral preferences and human behavior. New York: Springer-Verlag.

Porac, C., Coren, S., \& Duncan, P. (1980). Life-span age trends in laterality. Journal of Gerontology, 35, 715-721.

SCHWARTZ, M. (1990). Left-handedness and prenatal complications. In S. Coren (Ed.), Left-handedness: Behavioral implications and anomalies (Advances in Psychology, No. 67, pp. 75-97). Amsterdam: North-Holland.

Searleman, A., \& Fugagli, A. K. (1987). Suspected autoimmune disorders and left-handedness: Evidence from individuals with diabetes, Crohn's disease and ulcerative colitis. Neuropsychologia, 25, 367-374.

Searleman, A., Porac, C., \& Coren, S. (1989). The relationship between birth order, birth stress handedness and lateral preference: A critical review. Psychological Bulletin, 105, 397-408.

Smart, J. L., JefFery, C., \& Richards, B. A. (1980). A retrospective study of the relationship between birth history and handedness at six years. Early Human Development, 5, 79-88.

(Manuscript received April 29, 1993.) 